decision-makers and produced by scientists.

If quantitative models are here to stay, an important question to ask is how we can improve the way we create and apply models in science and policy. The authors provide some useful guidance by suggesting that we need to be more qualitative in how we model, for instance by recognizing that all current data and analysis point to sea levels rising for the foreseeable future, with some extreme scenarios that cannot be ruled out or even quantified probabilistically, but with a more honest admission that accurate prediction of longterm rates and totals is beyond our abilities.
Qualitative modelling supports adaptive decision-making under uncertainty, where commitments are tentative and continuously re-evaluated in the light of experience. Adaptive management does not exclude long-term planning, but it could help us to avoid the big mistakes made when we act as if we know more than we actually do. And as Useless Arithmetic details, making big mistakes based on the misuse of quantitative models is far more common than it should be.

Roger Pielke Jr is at the Center for Science and Technology Policy Research, University of Colorado/CIRES, Boulder, Colorado 80309, USA.

\title{
Science set in stone
}

\section{Swimming in Stone: The Amazing Gogo Fossils of the Kimberley \\ by John Long \\ Fremantle Arts Centre Press: 2007. 320 pp. $\$ 26.95$}

\section{Per E. Ahlberg}

Palaeontology is essentially a science of serendipity. Most of biology rests on the planning and execution of experiments that may or may not work; palaeontologists plan and carry out expeditions to look for fossils that may or may not be there. Of course, this base of collected specimens supports an analytical superstructure as organized and strategically constructed as any other. But behind the meticulous published analyses there lurks the faintly thrilling - or unsettling - realization that a loose rock left unturned, or a lunch break taken in a different spot on the hillside, could have caused a specimen or even a whole locality of critical scientific importance to remain undiscovered.

In Swimming in Stone, John Long tells the story of one of these critically important localities: Gogo in Western Australia. Here, at Go Go Station near Fitzroy Crossing in the tropical north of the state, yellow limestone nodules weathering out on a plain backed by oddly abrupt hills yield 380-million-year-old fossil fishes of such extraordinary perfection that, in some specimens, the jaws can be smoothly opened and closed without grating on their hinges. The whole landscape is, in fact, a gigantic fossil: the hills were once a barrier reef with outlying atolls, and the black soil of the plain is the mud that accumulated on the fore-reef slope. Limestone nodules formed around animal carcasses in this mud, preserving them perfectly to the present day. The locality was discovered in 1940 when the first fossil fish was collected by geologist

Curt Teichert, a refugee from Nazi Germany. Long, currently head of science at Museum Victoria . in Melbourne, has been collecting fossils there for more than 20 years.
After opening with a brief scene-setting introduction, including an imagined dive on the Gogo reef, the first main section of the book charts the history of the site from its discovery, through collecting trips by British and Australian teams, to the period since the 1980 s when Long became the driving force behind the collecting programme. Intertwined with this narrative of hard slog and lucky chance are vivid thumbnail portraits of the major players, such as Teichert, Harry Toombs and George Kendrick. There are also accounts of technical advances (crucially the development of fossil preparation using acetic acid, which revealed the full glory of the Gogo fishes) and scientific controversies over the Gogo material. These included not only issues of anatomical interpretation, but also a rather tense dispute between the Western Australian Museum in Perth and the then
British Museum of Natural History in London over the ultimate repository of type specimens, which, thankfully, was resolved amicably.

Long's writing style is breezy and engaging, showing the skill of an experienced writer. If you ever wanted to know what can befall you on a fossil-collecting expedition, it's all here - everything from broken-down vehicles, to dingoes trailing you in hopeful expectation of your death, to sharing the remote and isolated collecting area with an armed serial killer on the run. Helpful marginal notes explain scientific concepts such as phylogeny (the science of family trees) and fieldwork trivia such as death adders (beautifully camouflaged and extremely venomous snakes).

The second section of the book continues in the same accessible vein with an overview of the scientific importance of the Gogo fossils and their place in the emerging story of early vertebrate evolution. This is not a comprehensive account - for that I would recommend Philippe Janvier's Early Vertebrates (Oxford University Press, 1996) - and different researchers in the field will no doubt have their own disagreements with parts of it, but for those new to the subject it is an excellent introduction. It also demonstrates how progress in vertebrate palaeontology depends on the discovery of top-quality specimens, fossils so well preserved that anatomical and functional questions can be answered without ambiguity.

Of course, there are quibbles: giant dragonflies are not known from the Devonian, and Erik Jarvik and Erik Stensiö were not directors of the Swedish Museum of Natural History, although they did head the palaeozoology section.

There is also one serious omission:

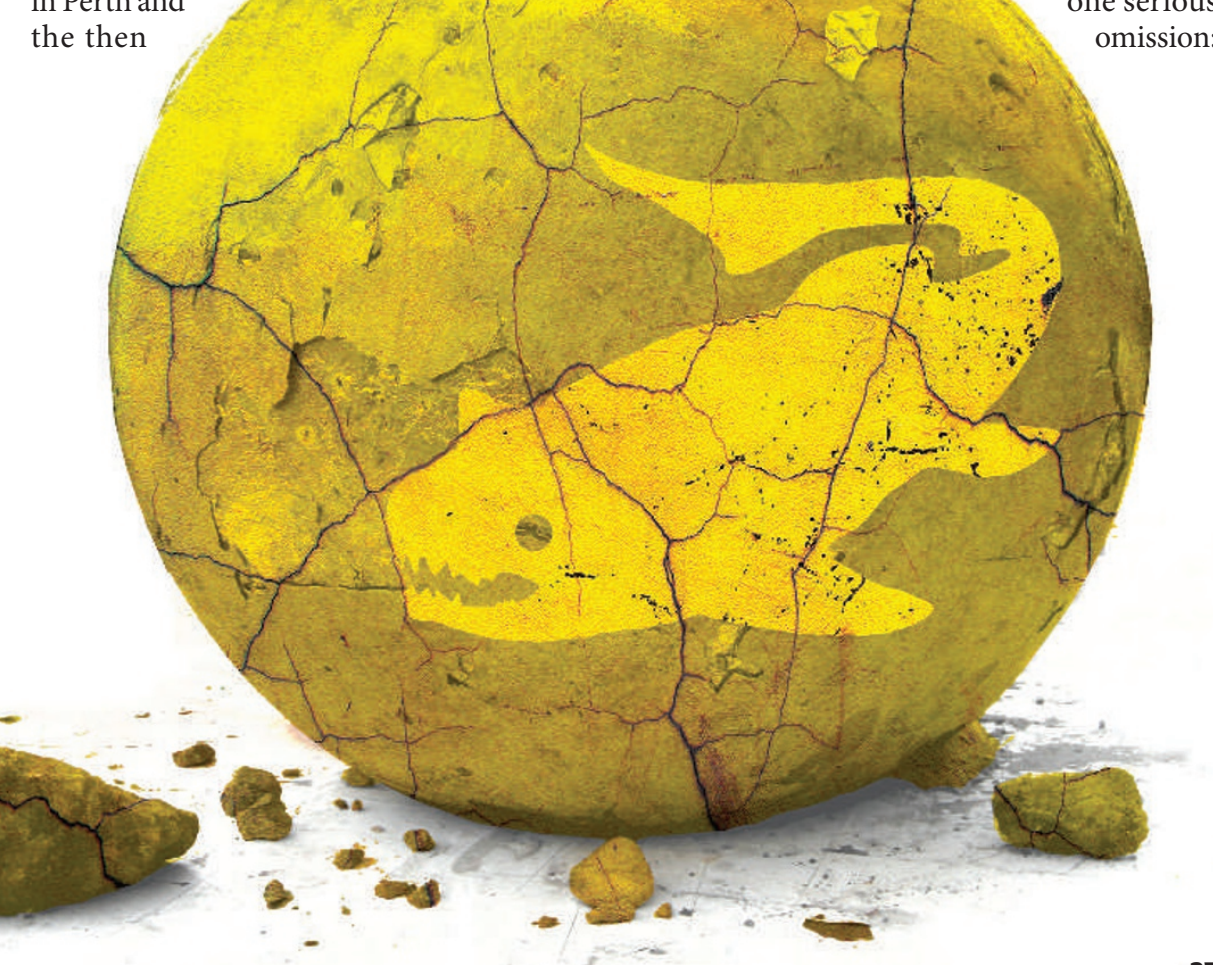


nowhere can I find a discussion of why the Gogo fossils are so exceptionally well preserved. Nodular preservation of fishes is common in the Devonian, but the specimens are usually nowhere near as perfect as these. Any future second edition of the book should certainly be expanded to include a chapter on this topic. But in the end these are the minor blemishes of a delightful book.

My first ever contribution to Nature, 18 years ago, was a News \& Views piece on John Long's Gogo fish research (Nature 337, 511-512, 1989). I ended it by saying that the scientific value of the Gogo fossils is incalculable, This remains just as true today, and Swimming in Stone is a worthy testament to the fact. Per E. Ahlberg is in the Department of Physiology and Developmental Biology, Uppsala University, Norbyvägen 18A, 75236 Uppsala, Sweden.

\section{An ode to symmetry}

\section{Why Beauty Is Truth: The History of Symmetry \\ by lan Stewart \\ Basic Books: 2007.304 pp. \$26.95}

\section{Joseph Mazur}

Had Keats lived long enough to read Ian Stewart's latest book, Why Beauty is Truth, he might have been inspired to write a sixth great ode, soft-piping sweet melodies in praise of symmetry. But what did Keats mean in Ode on a Grecian Urn when he wrote some of the most famous lines in English poetry: "Beauty is truth, truth beauty - that is all/ Ye know on earth, and all ye need to know"?

Stewart is onto something deep, something mathematicians must have been keenly aware of since Greeks began turning urns. What is the underlying beauty of mathematics? Is it the artful way a proof is expressed? Or is it something deeper - something guiding pythagorean and platonist mathematicians to see better, something at the molecular structure of mathematics, some "unravish'd bride of quietness", some "Attic shape" — that enlightens and delights us.

Stewart, a professor of mathematics at the University of Warwick, is renowned for his popular science books, but Why Beauty is Truth is without a doubt his finest. If it were just an authentic history of mathematics, it would be creditable. If it were only for its lively informal style, its historical characters, its intrigue ("The Galois group has a terrible secret"), its beautiful prose, it would be praiseworthy. Yet, its real uniqueness - its power - is in what it uncovers. It brings us the heart of why mathematicians pursue mathematics.

Beauty is not always as visible as the iridescent butterfly on the cover of Stewart's book. We are aware that it is not the dazzling colour that makes such an insect beautiful, but rather its shape, in particular its symmetry. It is this kind of beauty that Stewart's book reveals. We encounter it most obviously when we perceive it in geometry, in the wings of a butterfly, the sections of a cone, or the appearance of regular solids. But Stewart wants us to 'see' the invisible symmetries of algebra.

He starts with Évariste Galois, a young nineteenth-century French revolutionary who saw them when he discovered - ostensibly on the night before he died in a duel - how symmetry could be used to decide which polynomial equations could be solved by radicals and which could not. This is where the story of symmetry really takes off, with a pedantic question about solutions to equations. And it is where we are first told that symmetry is a process rather than a shape; it is a way to rearrange things. Symmetry then takes on a rigorous definition to become more than just a pleasing pattern. It had been an aesthetic part of geometry since Pythagoras, but Stewart tells us that Galois' revelation inspired others, starting with Sophus Lie's realization that geometric invariants associated with symmetry groups could determine the existence of solutions to differential equations. From this step forward, Lie groups and their associated Lie algebras emerge and invade. Symmetry then becomes deeply rooted in almost every area of mathematics, relativity and quantum physics, from the use of special and unitary orthogonal groups to the transformations of space-time and the gauge symmetries of Maxwell's equations, which led to the standard model of the theory of all fundamental particles.

How does Stewart do it? How can he make such phenomenally difficult material so easy to understand without giving sophisticated readers a sense that he is oversimplifying, and at the same time create something that is such a joy to read? He uses tangible things as examples, describing the fundamental forces of nature by throwing dishes on a kitchen floor. Towards the end he gives us a warning, as if apologizing for pedantry. "Bear with me," he says, "and don't worry too much about the odd piece of unexplained jargon. Sometimes we just need a convenient word to keep track of the main players." And with that, we stiffen, expecting the worst, but he goes on as before, escorting us through the deep forestal connections between mathematics and physics, guiding us with his inimitable clarity. But apart from some terms clear only to professionals, there's nothing to bear - we understand it.

When we come to Einstein, Stewart says: "Acres of print...have been devoted to Einstein's life and work." Yet when he tells us about Einstein's life and work, he makes us feel as if we've never heard it before. We may not fully understand the geometry of Minkowski space-time, the non-euclidean metrics or the bizarre consequences of relativity, but we come to believe we partly understand them - the ultimate aim of popular science narratives.

Why Beauty is Truth is a brilliant interweaving of politics, history and intrigue, with characters living ordinary lives, described in the spirit of a Russian novel.

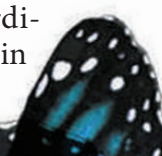

